\title{
Corpo estranho intracristaliniano
}

\author{
Intralenticular foreign body
}

Joyce Treinta Dalfré', Ana Carolina Igreja Leonor', Pedro Bertino Moreira ${ }^{3}$, Osmar Antônio Gaiotto Júnior ${ }^{4}$

\section{Resumo}

O relato mostra um caso de corpo estranho intracristaliniano de material metálico, em um paciente metalúrgico, com diagnóstico tardio, descrevendo a importância do exame clínico, a técnica cirúrgica empregada para a retirada do cristalino e a necessidade de divulgar e promover medidas preventivas nos ambientes ocupacionais e domésticos.

Descritores: Ferimentos oculares penetrantes/cirurgia; Corpos estranhos no olho/cirurgia; Lentes intraoculares; Extração de catarata; Implante de lente intraocular; Cristalino; Relatos de casos

${ }^{1}$ Residente do Departamento de Oftalmologia do Hospital Dia da Santa Casa de Misericórdia de Limeira - Limeira (SP)- Brasil; ${ }^{2}$ Residente do Departamento de Oftalmologia do Hospital Dia da Santa Casa de Misericórdia de Limeira - Limeira (SP)- Brasil; ${ }^{3}$ Preceptor do Setor de Córnea e Catarata do Departamento de Oftalmologia do Hospital Dia da Santa Casa de Misericórdia de Limeira - Limeira (SP)- Brasil;

${ }^{4}$ Coordenador do Departamento de Oftalmologia do Hospital Dia da Santa Casa de Misericórdia de Limeira - Limeira (SP)- Brasil.

Trabalho realizado no Serviço de Oftalmologia do Hospital Dia da Santa Casa de Misericórdia de Limeira - Limeira (SP) - Brasil.

Recebido para publicação em: 29/12/2008 - Aceito para publicação em 7/4/2009 


\section{INTRODUÇãO}

$\mathbf{0}$ straumas oculares, apesar dos poucos dados no Brasil, são comuns, podendo apresentar gravidades e grande importância social e econômica ${ }^{(1)}$.

Em pesquisas realizadas com os tipos de traumas oculares, corpo estranho é o_diagnóstico da maior parte dos casos.

Em estudo realizado em uma série de 386 pacientes com corpo estranho intraocular, houve uma frequência de 5,2\% de corpo estranho com localização intracristaliniana ${ }^{(2,3)}$.

Nos casos de corpo estranho intracristaliniano de pequena dimensão ou em localização periférica o diagnóstico pode ser omitido e passar despercebido durante vários anos $^{(2,3)}$.

Este relato tem por objetivo apresentar um caso de corpo estranho intracristaliniano dando ênfase ao seu diagnóstico e conduta.

\section{Relato de caso}

Paciente A.F.O.F., 70 anos, do sexo masculino, metalúrgico desde os 16 anos, procurou o nosso serviço com queixa de baixa acuidade visual em ambos os olhos, principalmente no olho esquerdo, há aproximadamente 4 anos. O mesmo era hipertenso em tratamento sem mais patologias sistêmicas ou oculares. Relatou que apesar do uso de óculos de proteção, apresentou vários episódios de corpos estranhos oculares em ambos os olhos, tendo feito uso de colírio anestésico e não procurando auxílio médico na maioria das vezes. Ao exame oftalmológico verificou-se acuidade visual com correção em olho direito 20/40 e olho esquerdo 20/80. À biomicroscopia de OD apresentava olho sem reação inflamatória com catarata cortical anterior $(3+/ 4+)$ periférica e inferior, nuclear $(1+/ 4+)$ e subcapsular posterior $(1+/ 4+)$. Em OE apresentava cicatriz corneana central discreta, porém acometendo toda a espessura corneana sugerindo lesão corneana autosselante, catarata cortical anterior $(2+/ 4+)$ periférica inferior, nuclear $(1+/ 4+)$ e subcapsular posterior $(3+/ 4+)$ (Figuras 1 e 2$)$. O cristalino apresentava opacidade focal paracentral inferior com pigmento de íris (aspecto de catarata polar porém com discreta descentração inferior da opacidade). A tonometria de aplanação aferida foi de $12 \mathrm{mmHg}$ (às 9 horas) em AO. Fundoscopia sem alterações, por oftalmoscopia binocular indireta. Foi solicitada ultrassonografia ocular de ambos os olhos que mostrou-se sem alterações e sem sinais de corpo estranho intraocular. Após análise do caso, foi realizada facectomia com implante de lente intraocular de
3 peças e $14 \mathrm{~mm}$ de diâmetro. Durante a cirurgia foi encontrado corpo estranho de aspecto metálico, medindo aproximadamente $1 \mathrm{~mm}$, aderido à cápsula anterior do cristalino (Figuras 3 e 4). O procedimento cirúrgico não apresentou intercorrências, tendo sido retirada a partícula metálica, extraído o cristalino e implantada a LIO. O paciente teve um pós-operatório sem complicações e recebeu alta com acuidade visual final com correção de 20/40 em olho direito e 20/30 em olho esquerdo.

\section{Discussão}

O trauma ocular, mesmo com avanços no diagnóstico e métodos terapêuticos, ainda é importante causa de perda visual, prejudicando o indivíduo e as empresas ${ }^{(4)}$, já que grande parte dos pacientes atendidos são vítimas de acidentes ocupacionais, como no caso acima relatado. Os métodos de observação direta geralmente são suficientes para o diagnóstico, embora o exame radiográfico e a ultrassonografia possam auxiliar nos $\operatorname{achados}^{(2,3)}$.

Devido à grande freqüência, os traumas oculares foram estudados por diversos autores, que propuseram diferentes técnicas de retirada de corpo estranho intracristaliniano ${ }^{(5,6)}$.

Elhchnig, em 1911, retirava-o através de incisão realizada no equador do cristalino com eletroímã ${ }^{(3,6)}$. François, em 1915, indicava a remoção através da ferida por onde havia penetrado o corpo estranho ${ }^{(3)}$. Riebel, em 1957, sugeriu a retirada isolada do corpo estranho, com substituição do humor aquoso pelo plasma do paciente adicionado ao gluconato de cálcio. Com isso, ocorria a formação de um coágulo que era retirado juntamente com o corpo estranho ${ }^{(6)}$. Moutinho, em 1969, defendia a realização de cirurgia intracapsular clássica com crioextração ${ }^{(3)}$.

As características do corpo estranho, como forma, tamanho e reatividade, associados à velocidade de entrada, trajetória e localização, irão determinar a extensão da lesão primária e as complicações tardias que incluem a endoftalmite ${ }^{(5)}$.

Atualmente, acredita-se que os corpos estranhos intracristalinianos não inertes, como por exemplo a madeira e os metais, devam ser retirados, mesmo nos casos de cristalino transparente, para evitar o desenvolvimento de complicações como siderose, calcose, argirose e uveítes intensas ${ }^{(5,6)}$.

Nos casos de corpo estranho de natureza inerte, como por exemplo o vidro, e na presença de cristalino transparente, a conduta pode ser expectante, devendo estes pacientes ser avaliados periodicamente. Nos casos 


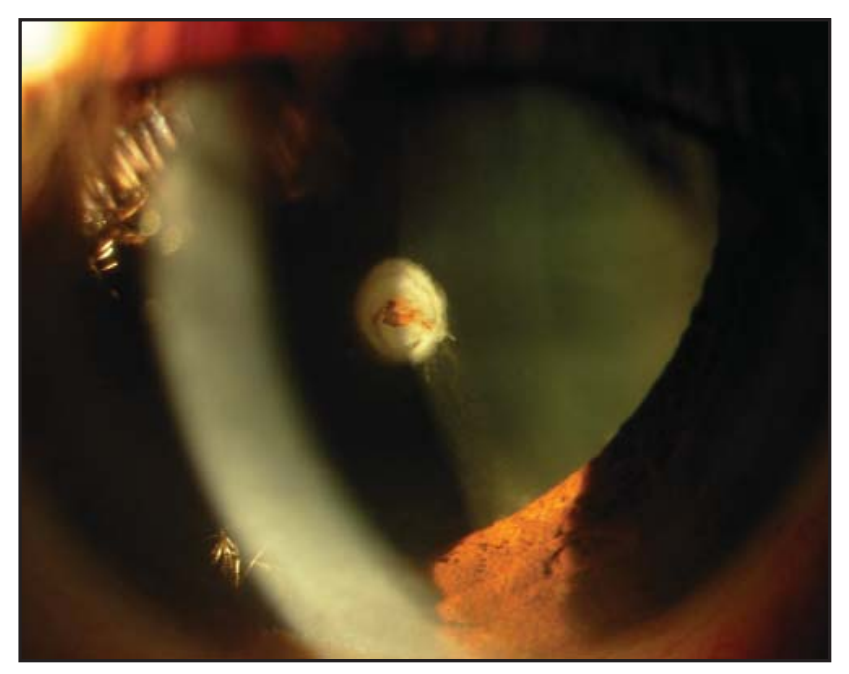

Figura 1: Biomicroscopia, detalhe mostrando cápsula anterior rota e opacificação adjacente

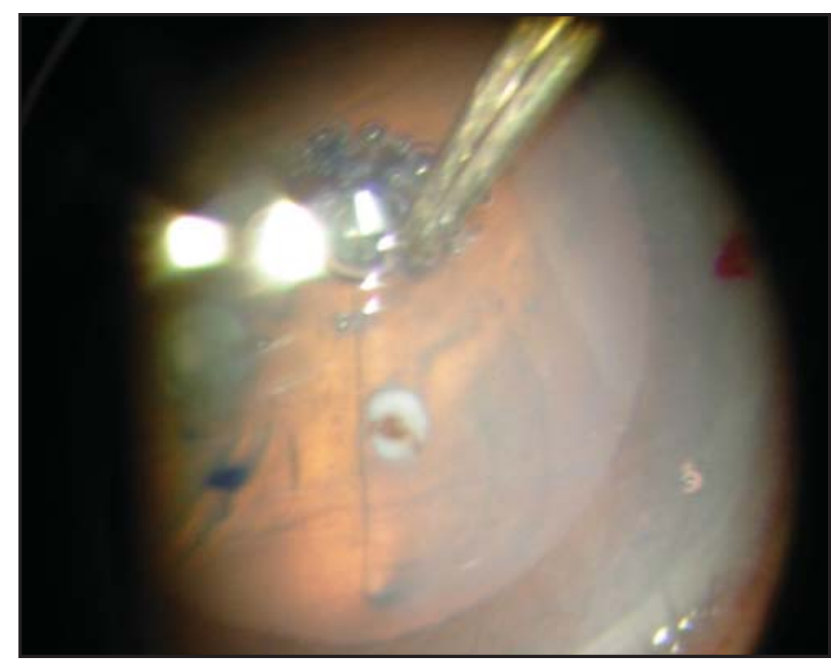

Figura 3: Intraoperatório, corpo estranho e cápsula sobre a córnea

de corpo estranho não inerte, cristalino opaco com catarata ou corpo estranho protuso para a câmara anterior, está indicada a remoção do corpo estranho e facectomia com implante de LIO, sempre que possível. A conduta cirúrgica deve ser adotada nos casos de corpo estranho de natureza ferrosa.

Nos casos de corpo estranho intracristaliniano, com lesão capsular menor que $2 \mathrm{~mm}$, o defeito possivelmente se autosselará e quando maior que $3 \mathrm{~mm}$, provavelmente ocorrerá formação de catarata progressiva ${ }^{(7)}$.

Existem três sinais ecográficos principais de um corpo estranho intraocular, que são de alta refletividade, reverberação e sombra acústica. No caso do corpo estranho encontrado em nosso relato, devido às suas pe-

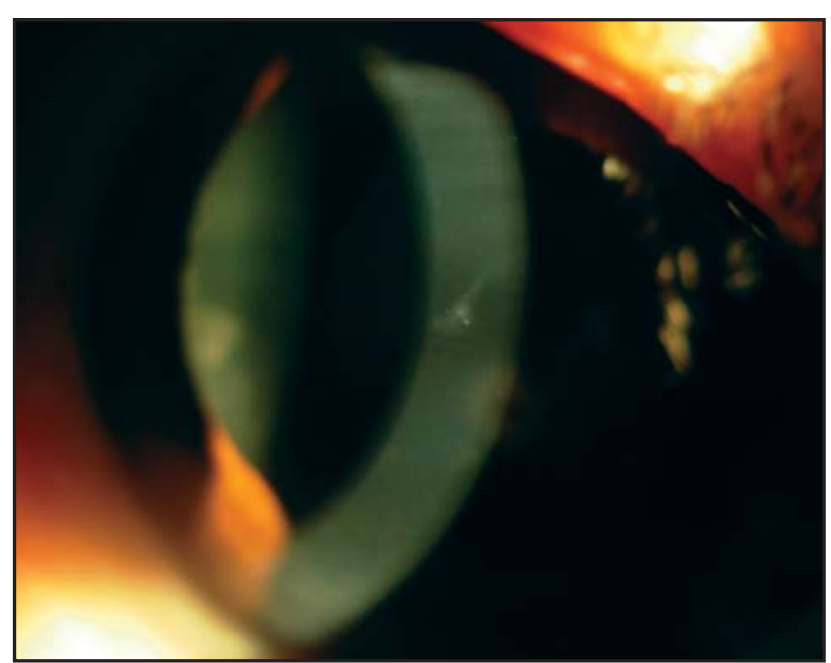

Figura 2: Biomicroscopia, detalhe mostrando porta de entrada corneana, lesão autosselante

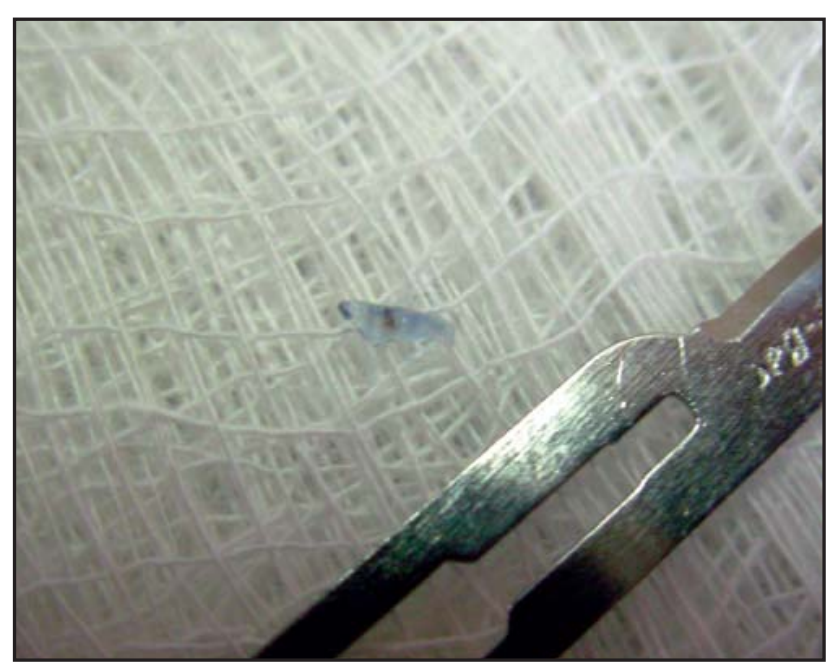

Figura 4: Pós-operatório imediato, corpo estranho aderido à capsula anterior

quenas dimensões, não se detectou nenhum dos três sinais ${ }^{(8,9)}$. Estes sinais poderiam evidenciar-se caso dispuséssemos em nosso serviço de um exame de ultrabiomicroscopia (UBM).

Dentre os materiais mais freqüentes que penetram o globo ocular estão as partículas metálicas, magnéticas ou não ${ }^{(10)}$. Estas se alojam, na maioria das vezes, no segmento posterior e são resultantes principalmente de acidentes de trabalho.

Nos casos de corpo estranho inerte, mesmo observando o cristalino transparente, a indicação cirúrgica precoce previne possíveis complicações futuras ${ }^{(2,5)}$.

Os casos de trauma ocular poderiam ser evitados com medidas preventivas já conhecidas e disponíveis. Os 
profissionais da área de oftalmologia deveriam enfatizar mais o uso de equipamento de segurança, tanto nas indústrias como no trânsito e trabalhos domésticos.

\section{Abstract}

The authors present a case of intralenticular metallic foreign body, in a metallurgist patient, with lateness diagnosis. They describe the importance of clinical exame, the surgical technical that was used to remove the foreign body of the crystalline and necessity to divulge and promote preventive ways at the occupational and domestical ambients.

Keywords: Eye injuries, penetrating/surgery; Eye foreign bodies/surgery; Lenses, intraocular; Cataract extraction; Lens implantation, intraocular; Case reports

\section{REFERÊNCIAS}

1. Parver LM. Eye trauma. The neglected disorder. Arch Ophthalmol. 1986;104(10):1452-3.

2. Ide $\mathrm{CH}$. Metallic foreign body in lens twenty-two years. Am J Ophthalmol. 1968;65(4):617-9.
3. Moutinho H. L'extraction des cops étrangers magnétiques du cristallin transparent. Ophthalmologica. 1969;1-3(1):64-74.

4. Adhikary HP, Taylor P, Fitzmaurice DJ. Prognosis of perforating eye injury. Br J Ophthalmol. 1976;60(11):737-9.

5. Myung JR, Santo RM, Suzuki H, Kara José N. Corpo estranho intracristaliniano. Rev Bras Oftalmol. 1988;47(2):105-10.

6. Riebel O. Extraction of magnetic foreign bodies from the clear lens. Am J Ophthalmol. 1979;88(5):935-8.

7. Fagerholm PP, Philipson BT. Human traumatic cataract. A quantitative microradiographic and electron microscopic study. Acta Ophthalmol (Copenh). 1979;57(1):20-32.

8. Abreu G. Ultra-sonografia ocular. Rio de Janeiro: Revinter; 1993.p. 192.

9. Byrne SF, Green RL, editors. Ultrasound of the eye and orbit. St. Louis: Mosby; 1992. p. 505.

10. Gulliver FD. Particles of steel within globe of the eye: cause, diagnosis, prevention, technic of removal and results. Arch Opthalmol. 1942;28(5):896-903.

\section{ENDEREÇO PARA CORRESPONDÊNCIA: \\ Joyce Treinta Dalfré \\ Rua Santa Cruz, 1070, apto.92 \\ CEP 13480-042 - Limeira - SP \\ Tel: (19) 34415250-fax}

E-mail: joycedalfre@yahoo.com.br 